\title{
A Revision Restoring Projection after Nipple Reconstruction by Burying Four Triangular Dermal Flaps
}

\author{
Ji Hun Kim, Hee Chang Ahn \\ Department of Plastic and Reconstructive Surgery, Hanyang University Seoul Hospital, Hanyang University College of Medicine, Seoul, Korea
}

Background Numerous techniques have been used to achieve long-term projection of the nipple following nipple-areola reconstruction. However, the reconstructed nipple loses projection over time. We describe a technique that uses local flaps to improve the lost projection of reconstructed nipples.

Methods Between November 2013 and March 2015, nine patients (11 nipples) underwent revisional nipple reconstruction for lost projection. Only $\mathrm{C}-\mathrm{H}$ nipple reconstructions were included in this study. The medical history of each patient was reviewed and photographs were taken in front and lateral views. All patients attended routine follow-up visits. Deepithelialized triangular flaps were made on all four sides of the nipple and buried in the opposite corners in order to augment the volume of the nipple. Anchoring sutures were used to attach each triangular flap on the side opposite their point of origin, and the resulting defects were closed directly.

Results This procedure was used successfully in nine patients (11 nipples). Adequate projection was achieved in all patients and no complications occurred. The average nipple height was 3 $\mathrm{mm}$ before operation, $7 \mathrm{~mm}$ one day after operation, $5 \mathrm{~mm}$ at the six-month follow-up, and $5 \mathrm{~mm}$ at the 12-month follow-up. The average nipple-areolar angle was $164^{\circ}$ before the operation, $111^{\circ}$ one day after the operation, $130^{\circ}$ at the six-month follow-up, and $133^{\circ}$ at the 12-month follow-up.

Conclusions The method described provides a solution to the loss of projection in reconstructed nipples. We recommend this technique because it leads to better projection, greater volume, and a more natural shape.

Keywords Nipples / Mammoplasty / Surgical flaps
Correspondence: Hee Chang Ahn Department of Plastic and Reconstructive Surgery, Hanyang University Seoul Hospital, Hanyang University College of Medicine, 222 Wangsimni-ro, Sungdong-gu, Seoul 04763, Korea

Tel: $+82-2-2290-8560$

Fax: +82-2-2295-7671

E-mail:ahnhc@hanyang.ac.kr

No potential conflict of interest relevant to this article was reported.

Received: 28 Oct 2015 • Revised: 1 Apr 2016• Accepted: 12 Apr 2016

pISSN: 2234-6163・ elSSN: 2234-6171 • http://dx.doi.org/10.5999/aps.2016.43.4.339・Arch Plast Surg 2016;43:339-343

\section{INTRODUCTION}

Nipple-areola reconstruction is the final stage of breast reconstruction, playing a crucial role in providing the breast with a natural appearance, especially when the patient is undressed.
Over the past four decades, many different techniques have been used to reconstruct the nipple following mastectomy. Some methods, such as nipple banking [1], nipple sharing, and nipple reconstruction with only a tattoo [2] are no longer used. Local pull-out flaps are currently considered to be more reliable and 


\section{Fig. 1. Nipple reconstruction with a $\mathrm{C}-\mathrm{H}$ flap}

(A) The incision line of the $\mathrm{C}-\mathrm{H}$ flap is drawn. (B) The $\mathrm{C}-\mathrm{H}$ flap is elevated. (C) The new nipple is reconstructed and the donor site is closed with a dog-ear correction. (D) Final shape of the nipple. The suture line resembles the letters ' $\mathrm{C}$ ' and ' $\mathrm{H}$ '.

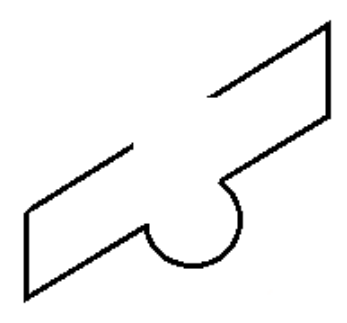

(A)

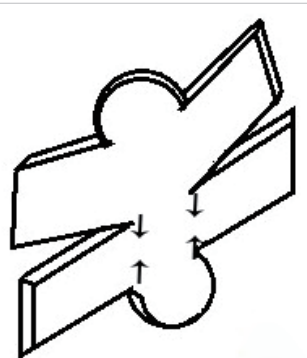

B

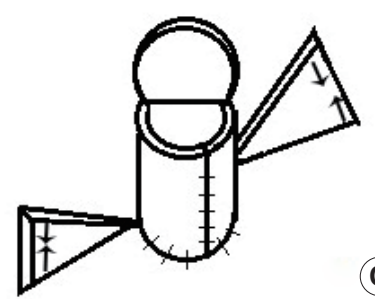

(C)

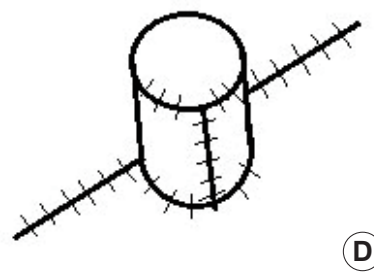

are the surgical technique of choice for nipple reconstruction [1,3-5]. However, the major disadvantage of reconstructing a nipple using local tissue is the long-term loss of nipple projection. Although the initial projection is adequate, all reconstructed nipples lose some projection over time. Indeed, in one study, lack of projection was found to be the most common factor for dissatisfaction in over $50 \%$ of patients who expressed dissatisfaction with the outcomes of breast reconstruction surgery [6].

In order to overcome the tendency of reconstructed nipples to flatten, a variety of methods and materials have been used to augment secondary nipple projection $[7,8]$. However, almost all of these techniques have poor experimental support and result in donor site morbidity.

Many articles have reported that dermal flaps can be used to correct inverted nipples $[9,10]$, but we have found no studies using dermal flaps to correct flattened nipples, and it occurred to us that dermal flaps might be used in such cases. The purpose of this report is to introduce a technique for secondary nipple projection involving the anchoring of four triangular dermal flaps. This technique achieves increased projection and volume, as well as providing the reconstructed nipple with a better shape.

\section{METHODS}

Between November 2013 and March 2015, re-projection surgery was performed on nine patients ( 11 reconstructed nipples) to treat lost projection in reconstructed nipples. Patients' dissatisfaction was the only surgical indication. The operations were performed by a single surgeon. The medical history of each patient was reviewed and photographs were taken in front and lateral views. The height of each nipple and the angle between the nipple and the areola of both sides were measured before the operation, one day after the operation, six months after the operation, and 12 months after the operation. Nipple height was defined as the length from the base of the nipple to the top of the nipple. A caliper was used to measure the nipple height. The height was measured perpendicular to the base of the nipple. The angle between the nipple and the areola was measured at the widest area with a protractor. All patients attended routine follow-up visits. Only $\mathrm{C}-\mathrm{H}$ nipple reconstructions using transverse rectus abdominis muscle flaps were included in this study. The $\mathrm{C}-\mathrm{H}$ flap, which is a modification of the $\mathrm{C}-\mathrm{V}$ flap, is named after the shape of the letters ' $C$ ' and ' $H$ '. Tip necrosis is a common complication of the $\mathrm{C}-\mathrm{V}$ flap. Furthermore, the shape of the nipple changes after the necrotic tissue of the tip heals. A C$\mathrm{H}$ flap is another option for nipple reconstruction, because tip necrosis does not occur. After nipple reconstruction with a C$\mathrm{H}$ flap, a larger dog-ear is created compared to the $\mathrm{C}-\mathrm{V}$ flap nipple reconstruction technique. However, after the dog-ear is corrected, it can be used for a dermal fat graft in the reconstructed nipple (Fig. 1). A dermal fat graft is not only useful for a small amount of volume augmentation, but also for preventing the loss of projection over time [11].

The operation was performed under local anesthesia. Four triangular flaps were designed on the nipple-areola complex. Four more triangular designs were made on the nipple to reduce the dog-ear and to narrow the base of the nipple (Fig. 2). The incisions were made over the design. Afterwards, the skin of the nipple-areola complex was dissected, and the epidermis was separated from the dermis over the planned flap area. De-epithelialized triangular flaps were created on all four sides of the areola, and a tunnel was formed in the deep plane below the nipple. The flaps were passed through the tunnels and buried in the four opposite corners in order to augment the volume of the nipple. Anchoring sutures were used to attach each triangular flap on the opposite side in order to narrow the base of the nipple, and the defects in the four areas were closed directly (Fig. 2).

\section{RESULTS}

Eleven cases in nine patients were evaluated in this study. The patients were $45-58$ years of age (mean, 50.9 years). The aver- 


\section{Fig. 2. Design of the four triangular flaps}

(A) Designs of the four triangular flaps and the four triangular dog-ear corrections. De-epithelialization was performed over the designs. (B) The four triangular de-epithelialized dermal flaps were elevated. (C) A tunnel was created under the nipple with a Metzenbaum Scissor. The figure only shows two flaps for better description. (D) The four de-epithelialized dermal flaps were passed through tunnels, buried in the four corners. The figure only shows two flaps for a better description. (E) The four buried triangular de-epithelialized dermal flaps were anchored on the opposite of their origin. The donor sites were closed directly. The figure only shows two flaps for a better description. (F) Final shape after procedure.
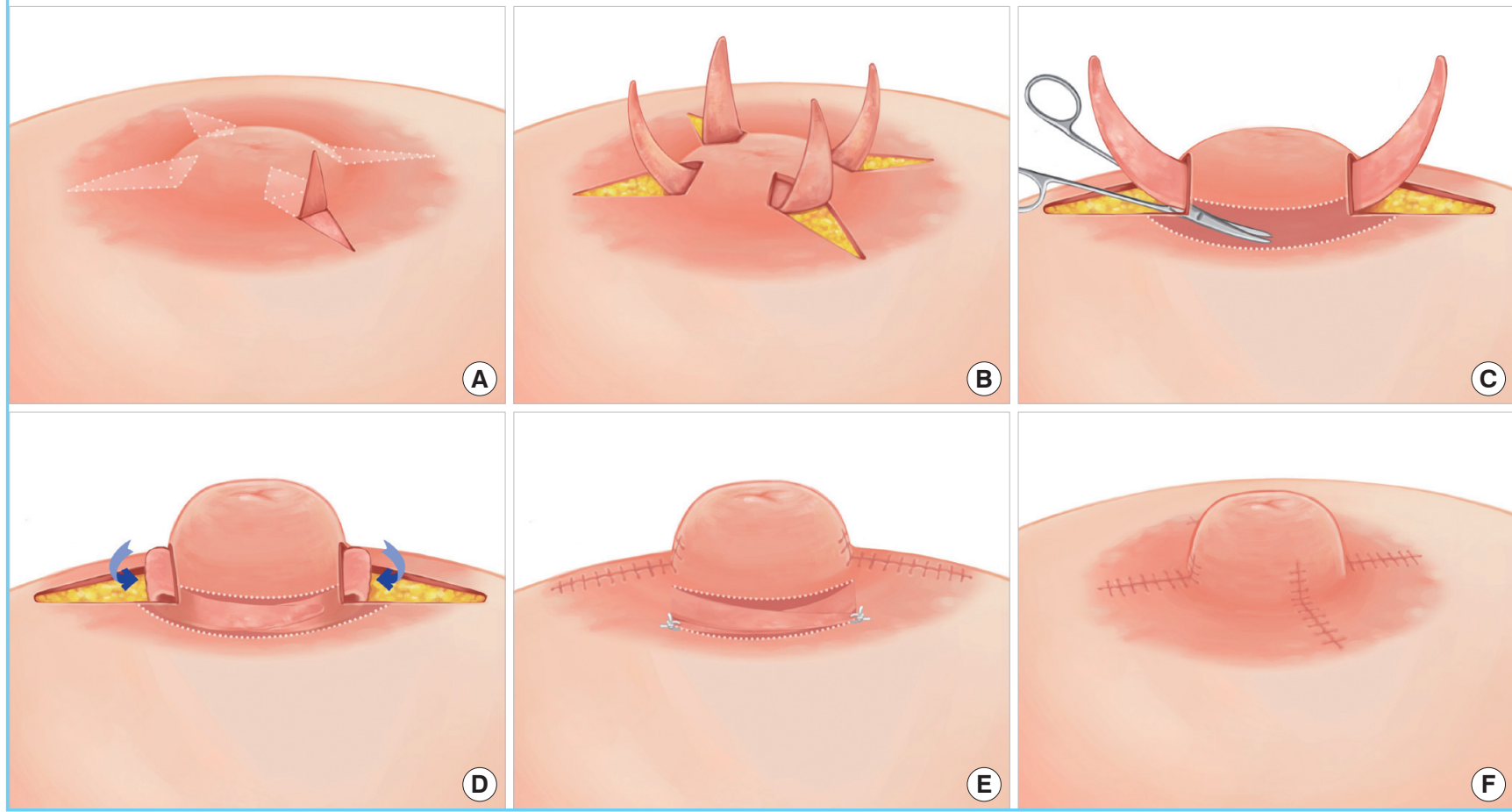

age period between primary and secondary reconstruction of the nipple was 13.67 months (range, 8-20 months). The average nipple height was $3 \mathrm{~mm}$ before secondary nipple reconstruction, $7 \mathrm{~mm}$ one day postoperatively, $5 \mathrm{~mm}$ at the six-month follow-up, and $5 \mathrm{~mm}$ at the 12 -month follow-up. The average height of the patients' natural nipples was $6 \mathrm{~mm}$ (range, 4-10 mm).

The average angle between the areola and nipple was $164^{\circ}$ before secondary nipple reconstruction, $111^{\circ}$ one day postoperatively, $130^{\circ}$ at the six-month follow-up, and $133^{\circ}$ at the 12 -month follow-up (Fig. 3). The average angle between the areola and nipple of the patients' natural nipples was $101^{\circ}$.

Patients were followed for 6-21 months postoperatively, with a median follow-up of 17 months. Two cases were followed for less than 12 months; therefore, only nine cases were included in the average figures for the 12-month follow-up.

No complications occurred in any patient included in this study.

\section{DISCUSSION}

One of the main purposes of nipple reconstruction is to create a three-dimensional nipple from a two-dimensional surface. However, a natural tendency exists for the reconstructed nipple to flatten and for the skin surface to return to its normal contour. Multiple causes of nipple flattening have been identified, including inadequate subcutaneous fat, internal and external pressure, poor flap design, delayed healing, and tissue memory [12]. Moreover, wearing a bra may result in external pressure on the surface of the breast, contributing to nipple flattening. The flattening ratio of reconstructed nipples is dependent on the quality of the skin, the type of breast reconstruction, and the surgical technique [13]. Many methods have been developed to overcome flattening after nipple reconstruction, but flattening remains a major concern. Secondary nipple reconstruction for nipple reprojection is needed to correct flattened reconstructed nipples, because loss of nipple projection is the reason for dissatisfaction in over $50 \%$ of dissatisfied patients [6]. However, few studies have addressed secondary nipple reconstruction for nipple reprojection. In one such study, Alloderm regenerative tissue matrix (LifeCell, Bridgewater, NJ, USA) was used to improve nipple projection in the reconstructed breast [12].

The importance of secondary nipple reconstruction has been overlooked, because it is mistakenly thought to be similar to primary nipple reconstruction. The role of secondary nipple reconstruction is to project a flattened nipple, not to correct the 


\section{Fig. 3. Preoperative and postoperative photographs}

(A) Preoperative frontal photograph. (B) Preoperative lateral photograph. (C) Frontal photograph one day after the operation. (D) Lateral photograph one day after the operation. (E) Frontal photograph 12 months after the operation. (F) Lateral photograph 12 months after the operation.
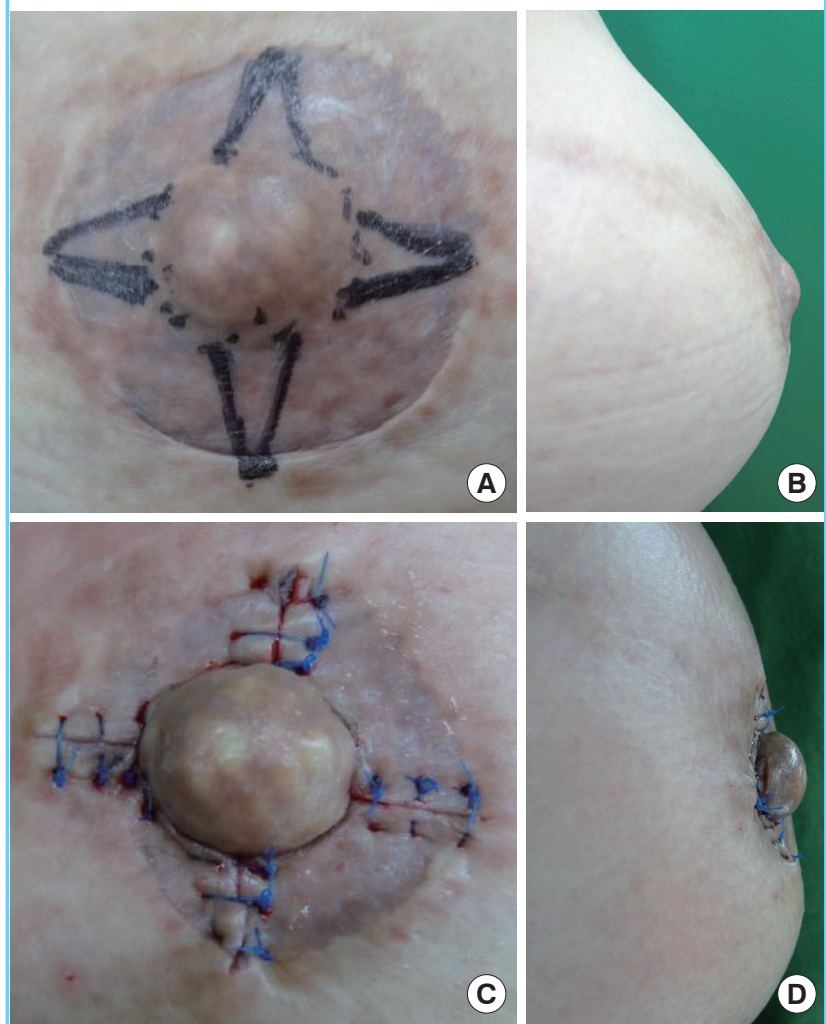

(C)
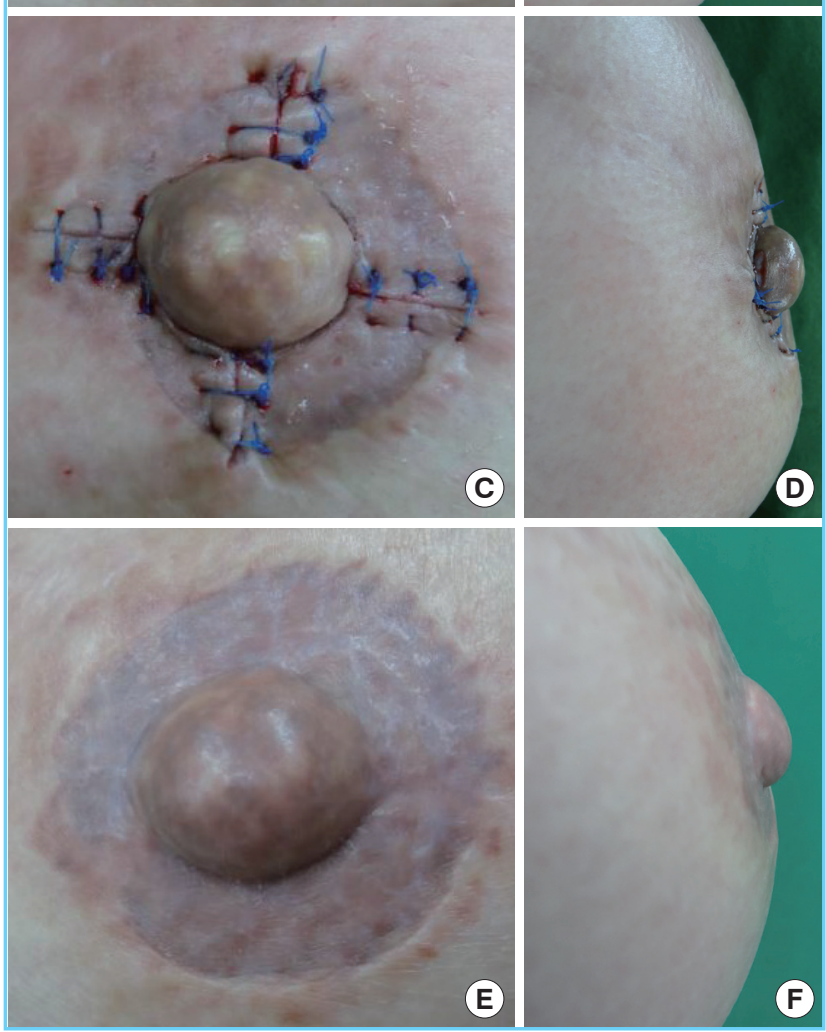

absence of a nipple. Only volume augmentation and correction of the nipple-areolar angle can improve the contour of the nipple. Methods that correct inverted nipples include suturing techniques [14], dermal flaps [15], and the use of dermis analogs [16]. Various types of dermal flaps have been used in the correction of inverted nipples, and we hypothesized that such flaps could be applied to secondary nipple reconstruction in the same way. In the correction of inverted nipples, limited-size dermal flaps are buried and anchored, because lactation must be preserved. However, in secondary reconstruction of the nipple, it is not necessary to preserve the lactation function, meaning that a greater volume of dermal flaps can be buried and strong anchoring sutures can be used to obtain a more acute nipple-areolar angle.

Park et al. [17] reported that the average height of the nipple was $5 \mathrm{~mm}$ in Korean women between 41 and 50 years of age. In this study, the average height of the natural nipple was $6 \mathrm{~mm}$, and the average height of the re-projected nipple was $5 \mathrm{~mm}$. The average height of the re-projected nipple was similar to the average Korean nipple height, in this case, the contralateral side. As far as we know, this is the first study measuring the angle between the nipple and areola. The angle between the nipple and areola of a reconstructed nipple tends to widen over time. Thus, narrowing the base of the nipple creates a more natural contour.

In this study, all patients were satisfied with the results. Although there was only an average $2 \mathrm{~mm}$ projection improvement in patients, by percentage, it was a $67 \%$ increase. The nipple shape appeared more natural postoperatively because the angle between the nipple and areola was decreased, in addition to the improvement in projection.

In this study, nipple projection gradually decreased over time, but tapered to a stable plateau after approximately six months to one year. Our study had a relatively short follow-up period, but other studies have also shown a stable plateau approximately one year after reconstruction $[13,18]$. The nipple-areolar angle likewise gradually increased over time, but stabilized after six months to one year. Two of our cases were followed for less than one year, but the other nine cases had successful results at the one year follow-up.

The limitation of this technique is the potential for scarification in four directions around the nipple. The shape of the tattooed nipple-areola complex can change after this revisional nipple restoration technique and so may need re-tattooing. However, the change was very subtle in all cases. No re-tattooing was provided after this procedure.

Many methods have been used in successful primary reconstruction of the nipple, but few reports have described successful secondary nipple reconstruction. The method reported here provides a solution to the loss of projection in reconstructed nipples. The use of four triangular dermal flaps and anchoring sutures on the opposite side of the flaps results in better projection and greater volume augmentation, improving the appearance and natural shape of the nipple. This method has proven to be reliable, effective, and safe, with long-lasting results, and may emerge as the method of choice for secondary nipple reconstruction. 


\section{REFERENCES}

1. Little JW. Nipple-areolar reconstruction. In: Cohen M, editor. Mastery of plastic and reconstructive surgery. Boston: Little, Brown; 1994. p.1342-8.

2. Bhatty MA, Berry RB. Nipple-areola reconstruction by tattooing and nipple sharing. Br J Plast Surg 1997;50:331-4.

3. Kroll SS. Integrated breast mound reduction and nipple reconstruction with the wraparound flap. Plast Reconstr Surg 1999; 104:687-93.

4. Thomas SV, Gellis MB, Pool R. Nipple reconstruction with a new local tissue flap. Plast Reconstr Surg 1996;97:1053-6.

5. Ramakrishnan VV, Mohan D, Villafane O, et al. Twin flap technique for nipple reconstruction. Ann Plast Surg 1997; 39:241-4.

6. Jabor MA, Shayani P, Collins DR Jr, et al. Nipple-areola reconstruction: satisfaction and clinical determinants. Plast Reconstr Surg 2002;110:457-63.

7. Bernard RW, Beran SJ. Autologous fat graft in nipple reconstruction. Plast Reconstr Surg 2003;112:964-8.

8. Tanabe HY, Tai Y, Kiyokawa K, et al. Nipple-areola reconstruction with a dermal-fat flap and rolled auricular cartilage. Plast Reconstr Surg 1997;100:431-8.

9. Kim DY, Jeong EC, Eo SR, et al. Correction of inverted nipple: an alternative method using two triangular areolar dermal flaps. Ann Plast Surg 2003;51:636-40.
10. Wu HL, Huang X, Zheng SS. A new procedure for correction of severe inverted nipple with two triangular areolar dermofibrous flaps. Aesthetic Plast Surg 2008;32:641-4.

11. Chia HL, Wong M, Tan BK. Nipple reconstruction with rolled dermal graft support. Arch Plast Surg 2014;41:158-62.

12. Nahabedian MY. Secondary nipple reconstruction using local flaps and AlloDerm. Plast Reconstr Surg 2005;115:205661.

13. Shestak KC, Gabriel A, Landecker A, et al. Assessment of long-term nipple projection: a comparison of three techniques. Plast Reconstr Surg 2002;110:780-6.

14. Peled IJ. Purse-string suture for nipple projection. Plast Reconstr Surg 1999;103:1480-2.

15. Burm JS, Kim YW. Correction of inverted nipples by strong suspension with areola-based dermal flaps. Plast Reconstr Surg 2007;120:1483-6.

16. Yamada N, Kakibuchi M, Kitayoshi H, et al. A method for correcting an inverted nipple with an artificial dermis. Aesthetic Plast Surg 2004;28:233-8.

17. Park IY, Kim MR, Jo HH, et al. Association of the nippleareola complexes with age, parity, and breastfeeding in Korean premenopausal women. J Hum Lact 2014;30:474-9.

18. Few JW, Marcus JR, Casas LA, et al. Long-term predictable nipple projection following reconstruction. Plast Reconstr Surg 1999; 104:1321-4. 